\title{
Radiochemical determination of longevity in flyingfish Hirundichthys affinis using Th-228/Ra-228
}

\author{
Steven E. Campana ${ }^{1}$, Hazel A. Oxenford ${ }^{3, *}$, John N. Smith ${ }^{2}$ \\ ${ }^{1}$ Marine Fish Division and ${ }^{2}$ Marine Chemistry Division, Bediord Institute of Oceanography, PO Box 1006, Dartmouth, \\ Nova Scotia, Canada B2Y 4 A2 \\ ${ }^{3}$ Bellairs Research Institute of McGill University, St. James, Barbados
}

\begin{abstract}
Radiochemical assays of fish otoliths using the radioisotope pair $\mathrm{Pb}-210 / \mathrm{Ra}-226$ have proven successful in determining the longevity of several long-lived fish species, but are unsuitable for determining ages less than about $3 \mathrm{yr}$. We tested the utility of the radioisotope pair Th-228/Ra-228 for determining the longevity of the four-winged flyingfish Hirundichthys affinis of the eastern Caribbean. A new decay equation was developed for interpreting radioactivity in whole otoliths characterized by a nonlinear growth history. Assay results on both whole otoliths and otolith cores indicated that the mean age of adult flyingfish was about $1 \mathrm{yr}$, and significantly less than $2 \mathrm{yr}$. The Th-228/Ra-228 radiochemical dating technique appears to be well suited for age determinations of fish up to age 5.
\end{abstract}

\section{INTRODUCTION}

The four-winged flyingfish Hirundichthys affinis is a prominent member of the eastern Caribbean pelagic fish community. It is also among the most important commercial fish species of the region, in terms of both landed weight and value to the economy (Mahon 1989). Current assessment of the resource is based on the assumption that the fish are fast growing and short lived, with a longevity of less than 2 yr (Mahon et al. 1986). This assumption comes from examination of the progression of $H$. affinis length frequency modes (Lewis et al. 1962, Storey 1983); annual rings have not been observed in either scales or otoliths of flyingfish (Hall 1955, Storey 1983). More recent studies have documented an extended spawning season and bimodal spawning peaks (Storey 1983, Khokiattiwong 1988), as well as seasonal interisland migration patterns (Oxenford 1993), all of which are likely to confound the interpretation of length frequency modes. Hence, little confidence can be ascribed to past estimates of

\footnotetext{
- Present address: Marine Resource and Environmental Management Program (MAREMP), University of the West Indies, Cave Hill, Barbados
}

longevity in the absence of age validation. Since use of incorrect ages artifactually changes apparent growth and mortality rates, age validation of flyingfish has considerable implications for both ecological studies and fisheries management in the region.

Radiochemical dating of the otolith is analogous to carbon-14 dating of archaeological artifacts, and is one of the few available means for age validation of many marine fish species. Otolith growth occurs through concentric accretions of calcium carbonate around a central nucleus, which show no evidence of resorption after deposition (Campana \& Neilson 1985). Naturally occurring radioactive calcium analogs which become incorporated into the growing otolith subsequently decay into radioactive daughter products, which are themselves retained within the acellular crystalline structure. Since the half-lives of the parent and daughter isotopes are known, the ratio between them is an index of elapsed time since incorporation of the parent isotope into the otolith. Radioisotope ratios in whole otoliths can be interpreted if there is sufficient information to model the growth in otolith mass through time (Bennett et al. 1982, Fenton et al. 1990, 1991, Smith et al. 1991). Interpretation of radioisotope ratios in extracted otolith cores is usually easier since it reflects elapsed time since core 
formation, which in turn is very similar to the age of the fish (Campana et al. 1990, Smith et al. 1991).

Recent applications of this technique using ratios of $\mathrm{Pb}-210 / \mathrm{Ra}-226$ have proven successful in determining the longevity of several long-lived species (Bennett et al. 1982, Campana et al. 1990, Fenton et al. 1991, Smith et al. 1991). The half-life of $\mathrm{Pb}-210$ (22.3 yr) makes isotope ratios such as $\mathrm{Pb}-210 / \mathrm{Ra}-226$ well suited to the age determination of long-lived fish, but they are not suitable for the age determination of short-lived species such as the flyingfish. On the basis of the relatively short half-life of Th-228 (1.9 yr), Turekian et al. $(1975,1982)$ and Le Foll et al. (1989) noted the utility of the radioisotope pair Th-228/Ra-228 in ageing short-lived invertebrates. Subsequently, Smith et al. (1991) presented preliminary Th-228/Ra-228 results on fish otoliths and suggested that the radioisotope pair might be well suited for ageing fish less than 5 yr old.

The objectives of the current study were to provide the first longevity estimates of a short-lived fish species using Th-228/Ra-228 assays, to compare the results of assays based on both whole otoliths and otolith cores, and to test current assumptions concerning the longevity of flyingfish in the eastern Caribbean.

\section{MATERIALS AND METHODS}

Otolith sampling and preparation. Adult Hirundichthys affinis were sampled from commercial catches landed in Barbados in 1990. Sagittal otoliths for whole-otolith assays were sampled between January 30 and February 1 from 82 fish with a mean fork length of $220 \mathrm{~mm}$ (SD = 10). The mean otolith weight was $94.9 \mathrm{mg}$. Sagittal otoliths for otolith-core assays were sampled from 100 fish with a mean fork length of $215 \mathrm{~mm}(\mathrm{SD}=9)$ on June 10. Extracted otoliths were wiped clean of adhering tissue and stored dry in paper envelopes until radiochemical analysis. Otolith volume was calculated as the product of otolith length, width and thickness as measured with a micrometer to the nearest $0.1 \mathrm{~mm}$. Similar measurements were taken of juvenile flyingfish otoliths $(n=50)$ collected as part of a research survey of the eastern Caribbean (H. A. Oxenford unpubl.). The relationship between otolith volume and juvenile fish age was then calculated by substituting the linear regression equation for fish length at age into the fitted exponential equation relating otolith volume to fish length. Juvenile fish age was determined using validated daily increment counts ( $\mathrm{H}$. A. Oxenford unpubl.). Otolith volume was used as a proxy for mass, rather than otolith weight, since measurements of the latter were not available.

Otolith cores were extracted from each otolith as rectangular blocks centred around the otolith nucleus, using a combination of a low-speed, diamond-bladed saw and thinning to the appropriate thickness with a whetstone. The location of the nucleus was assessed in relation to intact otolith morphology, and confirmed through sectioning of test samples. Block dimensions $(4.5 \times 2.5 \times 0.8 \mathrm{~mm})$ were selected so as to minimize the mean age of otolith core formation while maximizing the volume of material available for radiochemical analysis.

Surface contamination on the otolith cores was removed with a $30 \mathrm{sec}$ immersion in a $2: 1$ solution of $2 \%$ $\mathrm{HCl}$ and $32 \% \mathrm{H}_{2} \mathrm{O}_{2}$, followed by 3 successive rinses in distilled water. Cores were subsequently subdivided into two 50 core samples of about $0.9 \mathrm{~g}$ each.

Radionuclide measurements. After addition of Ra-226 and Th-229 yield tracers, the samples were digested in aqua regia for $4 \mathrm{~h}$, cooled and $20 \mathrm{ml}$ of hydrogen peroxide added drop-wise. The residue was redissolved in $100 \mathrm{ml}$ of concentrated $\mathrm{HNO}_{3}$ and $200 \mathrm{mg}$ of $\mathrm{Pb}\left(\mathrm{NO}_{3}\right)_{2}$ carrier was added. The solution was reduced in volume to $75 \mathrm{ml}, 25 \mathrm{ml}$ of fuming nitric acid was added, and the radium separated by coprecipitation with $\mathrm{Pb}\left(\mathrm{NO}_{3}\right)_{2}$ by chilling in an ultrasonic bath (Koide $\&$ Bruland 1975). The precipitate was centrifuged (saving the supernatant for Th analyses), dried in a counting vial and the Ra-226 and Ra-228 activities determined by gamma counting using a Canberra HPGE well detector having a relative efficiency of $20 \%$. The detector had a $103.5 \mathrm{ml}$ active volume, with a well diameter and depth of 20 and $35 \mathrm{~mm}$, respectively.

The supernatant was boiled to dryness and the residue dissolved in $8 \mathrm{NHNO}_{3}$. This solution was then passed through a $6.4 \mathrm{~cm}$ deep column of BIO-RAD AG1X4 ion-exchange resin in the nitrate form. Fe, $U$ and Am were washed from the column with $8 \mathrm{~N} \mathrm{HNO}_{3}$ and then Th was eluted with $12 \mathrm{~N} \mathrm{HCl}$. A second ionexchange column was used to purify the Th and the eluate was boiled to dryness. The sample was then redissolved in $\mathrm{H}_{2} \mathrm{SO}_{4}$ and plated onto a stainless steel disk at $1.1 \mathrm{~A}$ and $50 \mathrm{~V}$ for $2 \mathrm{~h}$. The alpha activities of Th-228 and the yield tracer, Th-229, were measured by alpha particle spectrometry using Ortec silicon surface barrier detectors.

Blank analyses were carried out using the same procedures, reagents, carriers and tracers as in the otolith analyses giving values of $0.010 \pm 0.005 \mathrm{dpm}$ for Th-228 and $0.050 \pm 0.020$ for $\mathrm{Ra}-228$.

Assumptions underlying radiochemical dating of otoliths. The Th-228/Ra-228 disequilibria ageing model for whole otoliths is based on the following assumptions:

(1) there is negligible, postformational, internal migration of radionuclides across internal otolith increments, i.e. the otolith constitutes a closed chemical system; 
(2) the uptake of Th-228 from seawater or other external sources is small compared to Ra-228 uptake;

(3) the uptake of $\mathrm{Ra}-228$ and $\mathrm{Th}-228$ is in constant proportion to the mass accumulation rate of the otolith.

Assumption (1) ensures that the chronological, radioactive disequilibria features of the otolith are preserved. This assumption is based on the absence of metabolic reworking of the acellular otolith (Campana \& Neilson 1985), and is supported by numerous studies reporting the formation of discrete chemical boundaries within the otolith (Tsukamoto 1988, Kalish 1989 , Gunn et al. 1992). However, it should be noted that this assumption is apparently invalid in some cellular systems, such as the vertebrae of sharks, where postformational transport of $\mathrm{Pb}-210$ has been observed (Weldon et al. 1987).

Assumption (2) ensures that the signal-to-noise ratio of the daughter/parent disequilibria signal is sufficiently great to ensure the practical viability of the method. Thorium is extremely particle-reactive in seawater, and as a result, is found primarily in the colloidal or particulate phases (Moran \& Buesseler 1992), thereby limiting its bioavailability for uptake in otoliths. This assumption can be validated by measurements on the otoliths of young fish and small discrepancies can be accommodated within a given model.

Assumption (3) is the most problematic to most whole-otolith applications of radium ageing, in part because it generally presupposes a knowledge of the otolith mass-growth rate as determined by unvalidated annulus counts. Fenton et al. (1990) detected a major violation of Assumption (3) in their measurements of $\mathrm{Pb}-210 / \mathrm{Ra}-226$ disequilibria in the whole otoliths of blue grenadier from southeastern Australian waters They measured an order of magnitude decrease in the Ra-226 concentration of whole otoliths of fish $>10 \mathrm{yr}$ old; the decrease may have been due to the habitat shift of the juveniles from radium-enriched, nearshore waters to the radium-poor offshore waters occupied by the adults. As noted earlier, the coring technique obviates the necessity of relying on Assumption (3), except for the initial (and usually negligible) period of core formation.

\section{RESULTS}

\section{Radioactive decay equations}

The processes and half-lives $\left(t_{1 / 2}\right)$ governing radium uptake and decay in otoliths are:

$$
\mathrm{Ra}-228 \stackrel{t_{1 / 2}=5.76 \mathrm{yr}}{\longrightarrow} \mathrm{Th}-228
$$

$$
\mathrm{Th}-228 \stackrel{t_{1 / 2}=1.91 \mathrm{Yr}}{\longrightarrow} \mathrm{Ra}-224
$$

The relationship between the Th-228/Ra-228 activity ratio in the otolith and its age can be determined by first considering the formation of the core of the otolith. The Ra-228 and Th-228 activities, $A_{\text {Ra-228 }}$ and $A_{\text {Th-228 }}$ and their ratio in the core at some future time (= age $t$ ) are given by the standard equations for this general decay scheme:

$$
\begin{gathered}
A_{\mathrm{Ra}-228}=A_{\mathrm{Ra}-228}^{0} \mathrm{e}^{-\lambda_{1} t} \\
A_{\text {Th-228 }}=A_{\mathrm{Ra}-228}^{0}\left[\lambda_{2} /\left(\lambda_{2}-\lambda_{1}\right)\right]\left(\mathrm{e}^{-\lambda_{1} t}-\mathrm{e}^{-\lambda_{2} t}\right) \\
+A_{\text {Th }-228}^{0} \mathrm{e}^{-\lambda_{2} t}
\end{gathered}
$$

where $\lambda_{1}=0.120 \mathrm{yr}^{-1}=3.3 \times 10^{-4} \mathrm{~d}^{-1}=$ the decay constant for Ra-228, $\lambda_{2}=0.363 \mathrm{yr}^{-1}=9.94 \times 10^{-4} \mathrm{~d}^{-1}=$ the decay constant for Th-228, and $\lambda_{2} /\left(\lambda_{2}-\lambda_{1}\right)=1.5$. As the otolith grows, new material is accreted to the outer surface having an initial activity ratio, $R^{0}=$ $A_{\mathrm{Th}-228}^{0} / A_{\mathrm{Ra}-228}^{0}$, while the inner core of the otolith has an activity ratio given by $A_{\text {Th-228 }} / A_{\text {Ra-228. In the general }}$ case, the total activities, $S_{\mathrm{Th}-228}$ and $S_{\mathrm{Ra}-228}$, in the otolith are calculated by integrating the product of the otolith mass-growth rate, $G(t)$ and a modifed form of Eq. (3) or (4) with respect to time, i.e.:

$$
\begin{aligned}
& S_{\text {Ra-228}}(\text { age })=\int_{t=0}^{\text {age }} G(t) A_{\text {Ra-228 }}^{0} \mathrm{e}^{\left.-\lambda_{1} \text { (age }-t\right)} \mathrm{d} t \\
& S_{\mathrm{Th}-228}(\text { age })=\int_{t=0}^{\text {age }} G(t)\left\{A_{\mathrm{Ra}-228}^{0}\left[\lambda_{2} /\left(\lambda_{2}-\lambda_{1}\right)\right]\right. \\
& \left.\left(\mathrm{e}^{-\lambda_{1}(\text { age }-t)}-\mathrm{e}^{-\lambda_{2}(\text { age }-t)}\right)+A_{\text {Th.228 }}^{0} \mathrm{e}^{-\lambda_{2}(\text { age }-t)}\right\} \mathrm{d} t
\end{aligned}
$$

Note the difference in the exponent of the decay term between Eqs. ( $3 \& 4$ ) and ( $5 \& 6$ ): the term (age - $t$ ) in Eqs. (5\& 6) is necessary to adjust for otolith material formed at time $t$ decaying over the period (age - $t$ ). Accordingly, the whole-otolith decay equations presented in Bennett et al. (1982) and Smith et al. (1991) are incorrect, although their final results are still valid due to their fortuitous selection of a linear mass-growth model (a constant mass-growth rate) for $G(t)$. Use of a nonlinear mass-growth model requires the application of Eqs. (5 \& 6) or significant error will result.

Selection of a linear otolith mass-growth model is often unrealistic, as evidenced by past requirements to piece together various linear growth segments in order to fit observed data (Bennett et al. 1982). A more versatile growth model is the cubic version of the von Bertalanffy model, often used to model fish weight nonlinearly as a function of age (Ricker 1979), as in: 


$$
\text { Weight }=W_{\infty}\left(1-e^{-k\left(t-t_{0}\right)}\right)^{3}
$$

where $W_{\text {sor }} k$ and $t_{0}$ are parameters to be estimated, and $W e i g h t$ and $W_{\infty}$ refer to otolith weight. The advantage of this model is that it can be used to fit size-at-age data containing both a growth inflection and an asymptote, as is often observed with otoliths. The first derivative of this equation, describing the absolute growth rate at age $[G(t)]$, is:

$$
G(t)=3 k W_{\infty}\left[\left(1-\mathrm{e}^{-k\left(t-t_{0}\right)}\right)^{2}-\left(1-\mathrm{e}^{-k\left(t-t_{0}\right)}\right)^{3}\right]
$$

Substituting Eq. (8) into Eq. (5), and integrating across the age of the otolith, gives the total activity of Ra-228 $\left(S_{\text {Ra-228 }}\right)$ in the whole otolith:

$$
\begin{aligned}
& S_{\mathrm{Ra}-228}= \\
& 3 k W_{\infty} A_{\mathrm{Ra}}^{0}\left[\left(\frac{-\mathrm{e}^{k\left(t_{0}-a g e\right)}}{k-\lambda_{1}}+\frac{2 \mathrm{e}^{2 k\left(t_{0}-a g e\right)}}{2 k-\lambda_{1}}-\frac{-\mathrm{e}^{3 k\left(t_{0}-a g e\right)}}{3 k-\lambda_{1}}\right)\right. \\
& \left.+\mathrm{e}^{-\lambda_{1} a g e}\left(\frac{\mathrm{e}^{3 k t_{0}}}{3 k-\lambda_{1}}-\frac{2 \mathrm{e}^{2 k t_{0}}}{2 k-\lambda_{1}}+\frac{\mathrm{e}^{k t_{0}}}{k-\lambda_{1}}\right)\right]
\end{aligned}
$$

Similarly, substituting Eq. (8) into Eq. (6) and then integrating gives the total activity, $S_{\text {Th-228, }}$ for Th-228 in the whole otolith:

$$
\begin{aligned}
& S_{\text {Th }-228}=3 k W_{\infty} A_{R a}^{0}\left(\frac{\lambda_{2}}{\lambda_{2}-\lambda_{1}}\right) \\
& {\left[\left(\frac{-e^{k\left(t_{0}-a g e\right)}}{k-\lambda_{1}}+\frac{e^{k\left(t_{0}-a g e\right)}}{k-\lambda_{2}}+\frac{2 \mathrm{e}^{2 k\left(t_{0}-a g e\right)}}{2 k-\lambda_{1}}\right.\right.} \\
& \left.-\frac{2 \mathrm{e}^{2 k\left(t_{0}-a g e\right)}}{2 k-\lambda_{2}}+\frac{\mathrm{e}^{3 k\left(t_{0}-a g e\right)}}{3 k-\lambda_{1}}-\frac{\mathrm{e}^{3 k\left(t_{0}-a g e\right)}}{3 k-\lambda_{2}}\right) \\
& +\mathrm{e}^{-\lambda_{1} a g e}\left(\frac{\mathrm{e}^{3 k t_{0}}}{3 k-\lambda_{1}}+\frac{2 \mathrm{e}^{2 k t_{0}}}{2 k-\lambda_{1}}-\frac{\mathrm{e}^{k t_{0}}}{k-\lambda_{1}}\right) \\
& \left.-\mathrm{e}^{-\lambda_{2} \dot{a} g e}\left(\frac{\mathrm{e}^{3 k t_{0}}}{3 k-\lambda_{2}}+\frac{2 \mathrm{e}^{2 k t_{0}}}{2 k-\lambda_{2}}-\frac{\mathrm{e}^{k t_{0}}}{k-\lambda_{2}}\right)\right]+A_{\mathrm{Th}-228 \text { term }}^{0}
\end{aligned}
$$

where the $A_{\mathrm{Th}}^{0}$ term is described by Eq. (9) (substituting $\lambda_{2}$ for $\lambda_{1}$ and $A_{T h}^{0}$ for $A_{\text {Ra }}^{0}$ ). Note that the $A_{T h}^{0}$ term will $=0$ unless Th-228 is incorporated along with Ra-228 during otolith growth.

The ratio of $S_{T h} / S_{R a}$ gives the otolith activity ratio at time $t=T$, where $T$ is either the age of the otolith at the time of fish collection, or the age of the experimentally defined otolith core. The activity ratio after this time is governed solely by the decay rate law:

$$
\frac{A_{\mathrm{Ih}}}{A_{\mathrm{Ra}}}\left(t^{\prime}\right)=\frac{\lambda_{2}}{\lambda_{2}-\lambda_{1}}\left(1-e^{\left.-\left(\lambda_{2}-\lambda_{1}\right)^{\prime}\right)}+\frac{S_{\mathrm{Th}}}{S_{\mathrm{Ra}}} \mathrm{e}^{-\left(\lambda_{2}-\lambda_{1}\right) t^{\prime}}\right.
$$

where $t^{\prime}=$ the time elapsed after otolith collection $($ time $T)=t-T$.

\section{Radiochemical assays}

Radiochemical assay results for whole otoliths and for otolith cores are given in Table 1 . The precision of the radiochemical age estimates was largely influenced by the assays for Ra-228. Counting uncertainties (2 SD) for Ra-228 averaged 40\%, while those for Th-228 were closer to $14 \%$.

\section{Estimation of flyingfish age from whole otoliths}

Since the radiochemical analysis of a whole otolith will always incorporate the gradient in Th-228/Ra-228 between the outer newly accreted otolith material and the inner previously deposited material, proper interpretation of such assays requires that the otolith mass growth-rate be known. The relationship between otolith size and fish size used to develop the equation relating otolith volume to daily age (see 'Methods') is given in Fig. 1. The otolith volume versus daily age curve was then fit with the cubic version of the von Bertalanffy equation (Eq. 7), using measurements of adult otolith volume to fix the asymptote independent of age (at $W_{\infty}=40 \mathrm{~mm}^{3}$ ). The least-squares fit to the data appeared to be good $\left(\mathrm{R}^{2}=0.94\right.$; Fig. 2), was insensitive to the age of the adult otoliths, and produced robust parameter estimates $\left(k=0.01265 ; t_{0}=\right.$ $10.989 \mathrm{~d}$ ). Radium and thorium activities based on this growth model produced the expected decay curves, with $A_{\mathrm{Ra}}$ peaking at about the time the otolith mass asymptote was reached (at about an age of $1 \mathrm{yr}$ ), and $A_{\text {Th }}$ increasing for several years thereafter (Fig. 3). Since the steepest portion of the $A_{\mathrm{Th}} / A_{\mathrm{Ra}}$ curve provides the best age discrimination, Fig. 3 indicates that ages of less than about 5 yr would be easiest to estimate with Th-228/Ra-228 ratios in whole flyingfish otoliths.

After using Eq. (11) to correct for postsampling decay, the mean age of the flying fish based on whole otoliths was estimated to be 0.65 yr (Table 1, Fig. 3). A collection date of 1 February 1990 indicates that the fish were hatched in late May or early June of 1989 (Fig. 4). Such a date is consistent with the major annual spawning peak of flying fish in the Caribbean (Storey 1983, Khokiattiwong 1988)

\section{Estimation of flyingfish age from otolith cores}

On the basis of the relationship between otolith size and fish length (Fig. 1) and otolith volume and fish age (Fig. 2), the core dimensions which were selected would correspond to a fish of about $12 \mathrm{~cm}$ in length and an age of $80 \mathrm{~d}$. The core age at which it had 
Table 1. Radionuclide measurements of whole otoliths and otolith cores of adult flyingfish. Data are given with 2 sigma counting uncertainties as of the counting date. Otolith and fish ages refer to the age of the otolith before and after correction for postsampling decay, respectively

\begin{tabular}{|c|c|c|c|c|c|c|c|}
\hline Sampling date & Counting date & $\begin{array}{c}\text { Sample wt } \\
\text { (g) }\end{array}$ & $\begin{array}{c}\mathrm{Ra}-228 \\
\left(\mathrm{dpm} \mathrm{g} \mathrm{g}^{-1}\right)\end{array}$ & $\begin{array}{c}\text { Th-228 } \\
\left(\mathrm{dpm} \mathrm{g}^{-1}\right)\end{array}$ & Th-228/Ra-228 & $\begin{array}{l}\text { Otolith age } \\
\text { (yr) }\end{array}$ & $\begin{array}{c}\text { Fish age } \\
(y \mathrm{r})\end{array}$ \\
\hline \multicolumn{8}{|l|}{ Whole otoliths } \\
\hline 1 Feb 1990 & $26 \mathrm{Apr} 1990$ & 1.10 & $0.58 \pm 0.23$ & $0.16 \pm 0.02$ & $0.28 \pm 0.12$ & 1.27 & 1.04 \\
\hline 1 Feb 1990 & 26 Apr 1990 & 1.04 & $1.11 \pm 0.44$ & $0.15 \pm 0.02$ & $0.14 \pm 0.06$ & 0.68 & 0.45 \\
\hline 1 Feb 1990 & 26 Apr 1990 & 0.55 & $1.42 \pm 0.57$ & $0.20 \pm 0.03$ & $0.14 \pm 0.06$ & 0.68 & 0.45 \\
\hline \multicolumn{8}{|l|}{ Otolith cores } \\
\hline 10 Jun 1990 & 16 Jul 1991 & 0.91 & $0.57 \pm 0.23$ & $0.14 \pm 0.02$ & $0.25 \pm 0.11$ & 0.93 & -0.17 \\
\hline 10 Jun 1990 & 16 Jul 1991 & 0.89 & $0.56 \pm 0.22$ & $0.20 \pm 0.03$ & $0.36 \pm 0.15$ & 1.32 & +0.22 \\
\hline
\end{tabular}

reached $50 \%$ of its core volume (core ${ }_{50}$ ) was about 2 mo. The mean radiochemical age of the otolith core samples at the time of counting was 1.13 yr (Table 1). Given the 13 mo interval between collection and analysis, the mean estimated fish age at the time of collection would be 0.03 yr (Fig. 3). Based on counting statistics alone, the $95 \%$ confidence interval for the mean age was -0.47 to 0.53 yr. Taken at face value, this age range would appear to be too young for adult flying fish. However, the above confidence interval does not take into account uncertainty due to errors in centering the otolith nucleus within the extracted

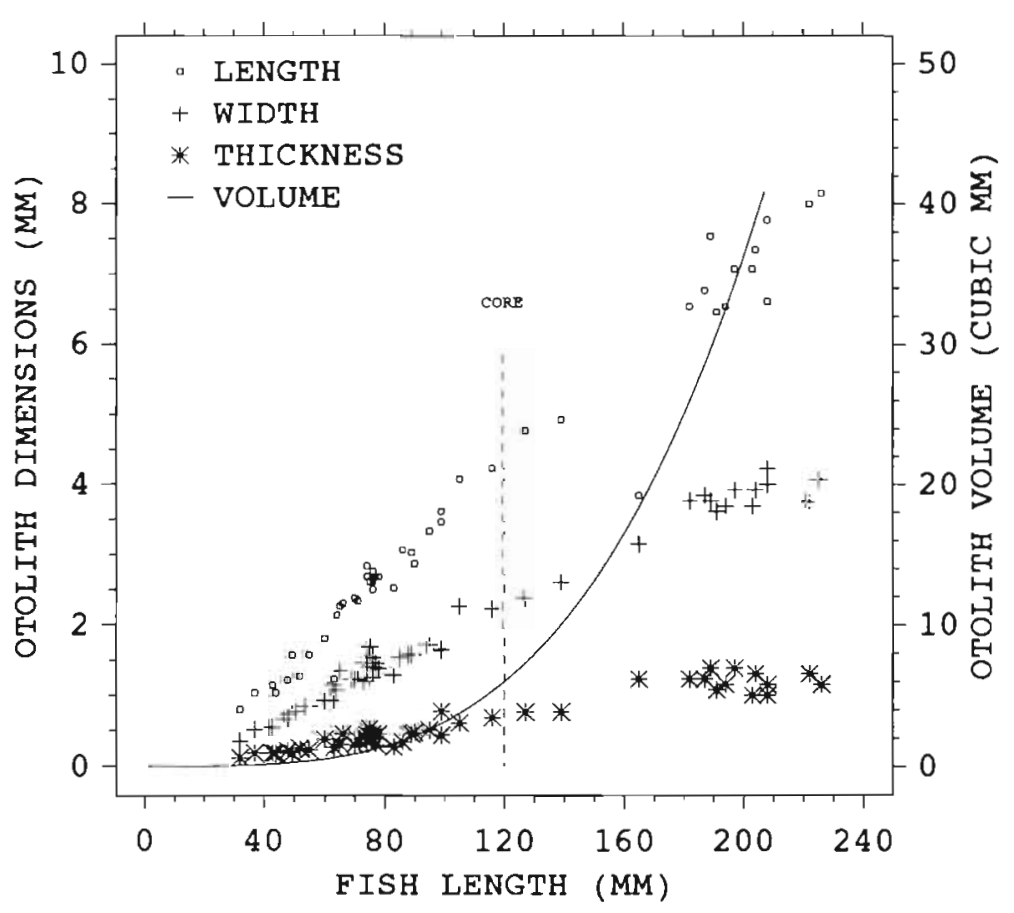

Fig. 1 Hirundichthys affinis. Dimensions of flyingfish otoliths as a function of fish length. Otolith volume was calculated as the product of length, width and thickness. Dimensions of the extracted otolith core, centred around the nucleus, are also shown otolith core. Since errors in positioning the nucleus symmetrically within the extracted core will always result in the inclusion of recently deposited material on 1 or more axes, positional error can only result in bias towards a more recent date of core formation. We were unable to quantify the magnitude of this bias. However, simple observation indicated that almost all of the potential error in centring the nucleus within the extracted core was associated with the otolith width (dorso-ventral) and thickness (proximo-distal) growth axes, from which relatively little outer material was removed. Therefore, we calculated the upper limits of positioning error by assuming that cores of the appropriate dimensions were taken, not from the centre of the otolith, but from the edge of the dorsoventral and proximo-distal surfaces. Under such conditions, the mean age of core formation increased 3 to 4 mo over the ideal core mean age of 2 mo. Use of rectangular cores (for logistical reasons) rather than oval cores (more representative of actual otolith growth) would introduce additional bias, due to the incorporation of more recently formed material. On the basis of our rough calculations, it appears that positional error could have increased the core mean age by as little as 1 mo, and as much as 6 mo. A 2 to 3 mo error appeared to be most plausible. Such errors would make the otolith core somewhat older than was originally intended, and thus unintentionally reduce the final fish age estimate by an equivalent amount.

The mean back-calculated hatch date of adult flying fish based on the age estimates of the otolith-core samples was most consistent with spawning in the secondary annual spawning peak in December 


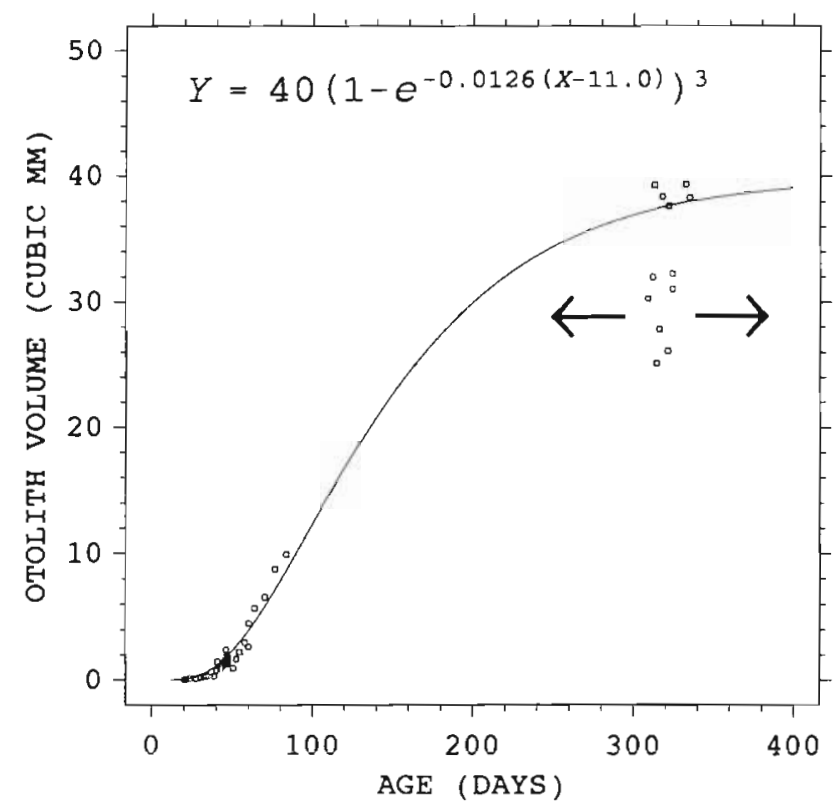

Fig. 2. Hirundichthys affinis. Otolith volume as a function of fish age. The cubic version of the von Bertalanffy growth curve has been fitted to otolith volume at age data for knownage fish. Observed adult otolith volumes have also been plotted; arrows indicate the uncertainty in their age, but these data were not used to fit the curve

(Fig. 4) (Storey 1983, Khokiattiwong 1988). Such an estimate is well within the range of uncertainty expected of radiochemical counting and even minimal nucleus positioning error. Indeed, the confidence interval for the cored sample hatch date also overlapped with that from the whole-otolith samples and the primary annual (May) spawning peak, albeit at the very edge of the interval (Fig. 4). A December 1989 spawning period would have implied an adult fish age of 6 to 7 mo at the time of capture, while a May 1989 spawning period would have implied a mean age of 13 mo.

Most importantly, neither the whole-otolith nor the otolith-core radiochemical age estimate were consistent with an adult age of either 18 or 25 mo (i.e. the age expected if the fish had been spawned the year before).

\section{DISCUSSION}

Radiochemical analysis of both whole otoliths and otolith cores indicated that adult flyingfish were about 1 yr old, rather than 2. Furthermore, both sets of age determinations were consistent with the known spawning pulses of flyingfish in the Barbados area (Storey 1983, Khokiattiwong 1988, Lao 1989). The whole-otolith sample was probably hatched in May, the primary spawning period. While the exact hatch date of the otolith-core sample was more difficult to determine, the age of the sample was most consistent with a December 1989 hatch date, which is the secondary spawning period. Such a hatching pattern is consistent with the expectation that an annual fish
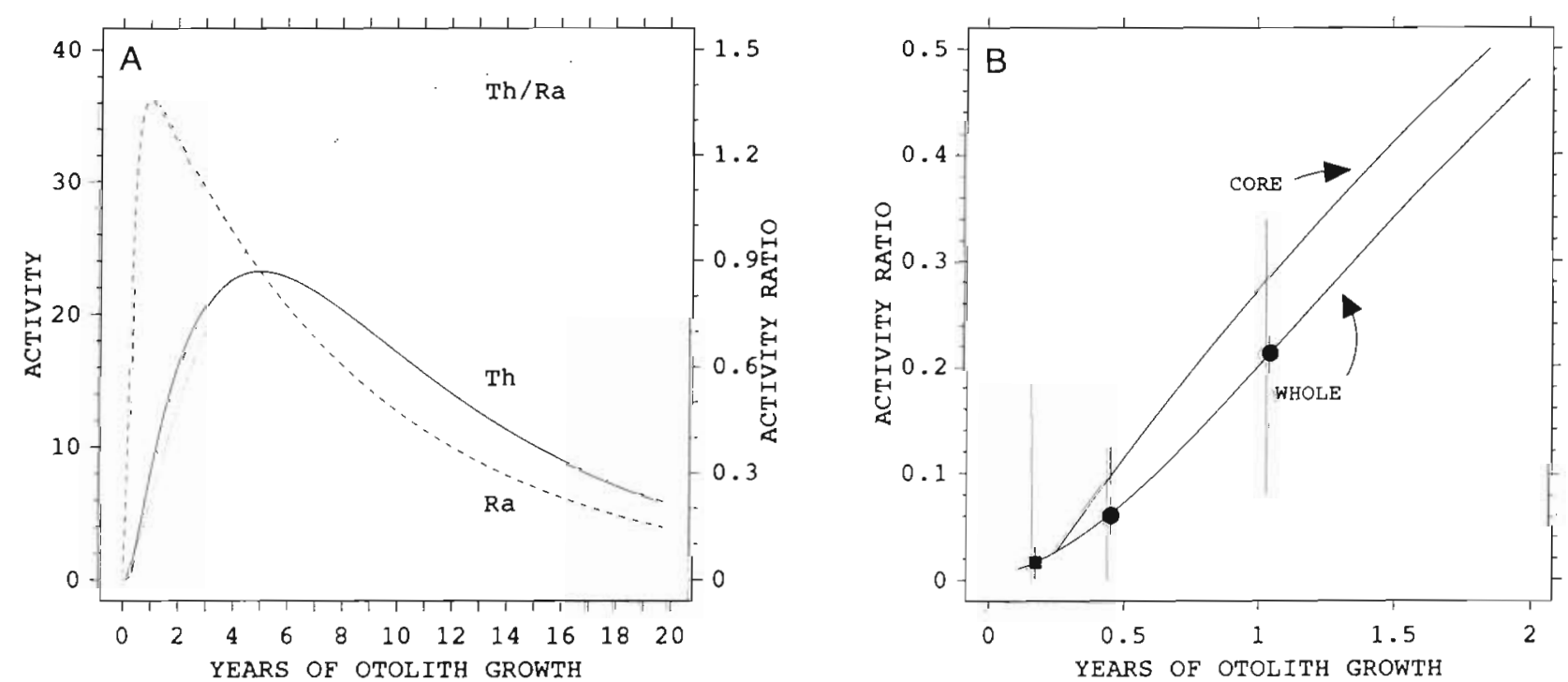

Fig. 3. Hirundichthys affinis. (A) Total activity (dpm) of Th-228, Ra-228 and their ratio in whole flyingfish otoliths as a function of fish age. The rate of otolith growth is as shown in Fig. 2, where the input of newly accreted otolith material becomes minimal after a fish age of 1 yr. Transient equilibrium for the Th:Ra ratio is at a value of 1.5. (B) Close-up of the activity ratio curve shown in (A), plotted over a 2 yr period, for both whole otoliths and 80 -d otolith cores. Observed activity ratios ( \pm 2 SD) for whole otoliths ( ) and otolith cores ( ), corrected for postsampling decay, are also shown. A core assay result which was negative when decaycorrected (age $=-0.17 \mathrm{yr}$ ) is not shown 


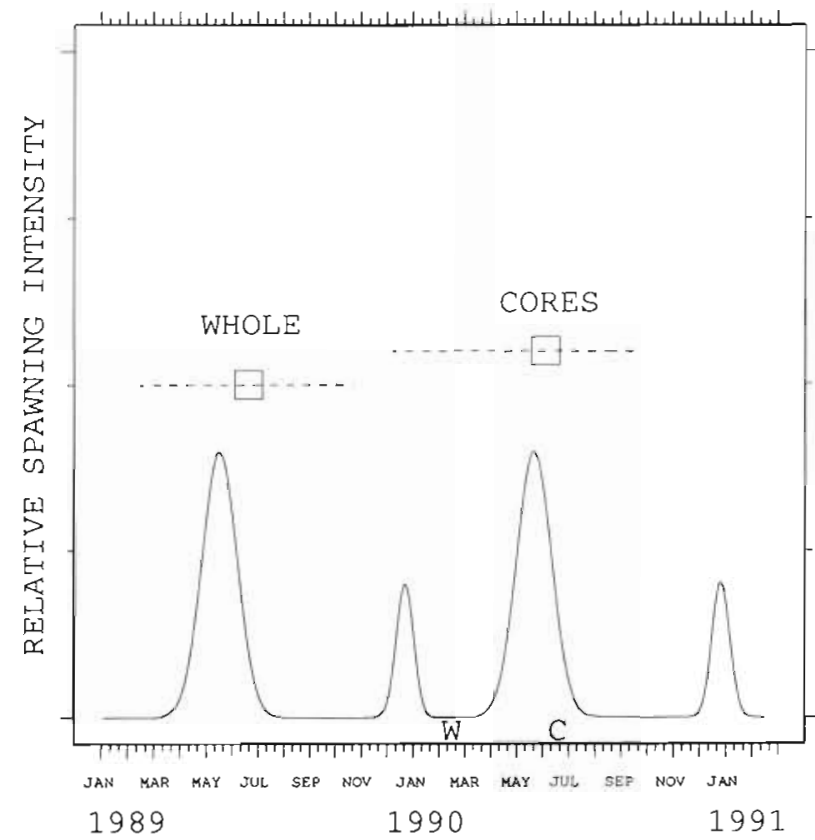

Fig. 4. Hirundichthys affinis. Back-calculated flyingfish hatch dates determined from radiochemical assays of whole otoliths (Whole) and otolith cores (Cores) in relation to approximate spawning intensity. Horizontal uncertainties around the estimated hatch dates represent $1 \mathrm{SD}$, and in the case of the core sample, a 2 to 3 mo bias associated with inaccurate positioning of the otolith nucleus in the centre of the extracted core. $W$ and $C$ represent the dates of Whole and Core sample collection, respectively. A flyingfish longevity of 1 yr implies that both Whole and Core samples were hatched either in May or December 1989

species with a seasonal fishery and migration pattern would enter the fishery on an age- or size-structured basis. As such, the older fish (such as those hatched in May 1989) would be caught first (e.g. in February 1990), followed some months later by those hatched later in the year (e.g. in December 1989).

A radiochemically determined flyingfish longevity of $1 \mathrm{yr}$ is consistent with previous suggestions based on length-frequency analysis (Mahon et al. 1986). It is also consistent with presumed mortality rates based on the complete absence of adult flyingfish tag returns in subsequent fishing seasons (Oxenford 1993). Previous studies have been unable to determine longevity, or even the age structure of the fished population, due to the rapid reduction in growth rates associated with the onset of sexual maturity. Examination of the otolith microstructure provided accurate estimates of growth rate through the first 3 mo of life, but daily increment widths became too difficult to interpret at greater ages (Oxenford et al. unpubl.). Given the apparent absence of annular rings on scales and otoliths (Oxenford 1986), radiochemical age determinations are, at present, the only viable means of confirming longevity in this species.

Validation of a 1 yr lifespan for Hirundichthys affinis has important implications for its management. Not only can an annual species be harvested at a greater rate than can a longer-lived species, but the value of annual catch per unit effort data for conducting annual stock-recruitment risk assessments is confirmed (Mahon 1986).

The use of Th-228/Ra-228 isotopes in this study extends the value of radiochemical age determinations over a much broader range of ages and species than was previously possible. Previous studies using $\mathrm{Pb}-210 / \mathrm{Ra}-226$ were well suited to long-lived species (15 to 150 yr) (Bennett et al. 1982, Campana et al. 1990, Fenton et al. 1990, 1991, Smith et al. 1991), but are inappropriate for shorter-lived species, including many of the tropical and temperate pelagic fishes. The Th-228/Ra-228 isotopes are ideally suited to age determinations in the range of 0 to $5 \mathrm{yr}$, although our unpublished data suggest that the useful age range is somewhat narrower ( 0 to 2 yr). As is the case with $\mathrm{Pb}-210$ / Ra-226 assays, the greatest analytical uncertainty lies with the radium assays, due to its proximity to background levels. As a result, and despite the young ages to which the Th-228/Ra-228 assay is suited, the relative uncertainty in the resulting ages is fairly large, thus explaining our inability to differentiate among withinyear spawning pulses. Use of additional samples would have helped reduce this uncertainty.

In principle, age determinations based on otolith core assays should always be more reliable than those based on whole otoliths, since the need for modelling the growth of the otolith is eliminated. In a comparison of radiochemical assays of intact and cored otoliths from redfish Sebastes marinus, Smith et al. (1991) found that the latter provided less ambiguous results, presumably due to the complex growth pattern of the adult otoliths after the onset of sexual maturity. Fenton et al. (1990) also reported difficulties in interpreting whole-otolith assays of blue grenadier Macruronus novaezelandiae, due to differences in the chemical environments of juveniles and adults which resulted in ontogenetic variations in the uptake of Ra-226 into the otolith crystal structure. However, neither of the above factors appear to have complicated the interpretation of the flyingfish results, in part because all flyingfish life stages share a similar pelagic marine environment, and in part because there was relatively little room for error in the construction of the otolith-mass growth curve.

The nonlinear otolith-mass growth decay model presented in this study offers several advantages over the decay models based on linear growth used previously to calculate whole-otolith isotope activity ratios. An obvious advantage is the increased versatility and 
accuracy in modelling the nonlinear growth patterns so typical of fish otoliths (Summerfelt \& Hall 1987). Even a linear growth pattern can be accurately modelled using Eq. (7). However, an equally important feature is the ability to use measurements of adult otolith mass to fit an asymptote of the growth curve (if present) without prior knowledge of adult age. Such an advantage is illustrated in Fig. 2, in which the fitted shape of the otolith growth curve is insensitive to the true age of the adults (which is, of course, unknown). Note that Eqs. $(9 \& 10)$ can be applied to whole-otolith assays of all radioisotope pairs, not just $\mathrm{Th}-228$ and $\mathrm{Ra}-228$.

Use of otolith cores circumvented all assumptions concerning otolith growth patterns and consistency in the uptake of thorium or radium subsequent to the formation of the core, and thus avoided the accompanying uncertainty. However, use of cores introduced additional uncertainty associated with error in correctly positioning the core. Hence, the optimum size of the otolith core is: (1) sufficiently small so as to reduce variability due to subsequent otolith growth and variability in Ra/Ca uptake, and (2) sufficiently large so as to reduce the amount of labour involved in core extraction from the otolith.

The radiochemical assays of the whole otoliths appear to have provided an accurate estimate of fish age. The otolith core samples were apparently less accurate, although still within acceptable bounds. Precision in both sets of samples was limited by the relatively low number of samples. However, the reduced precision in the core results was also caused by counting uncertainties associated with the 1 yr delay between collection and assay of the sample. As with all radiochemical dating studies, the discrimination power of the assays necessarily decreased with time as the isotope activity ratios approached transient equilibrium. On the other hand, there is no evidence to suggest that in situ contamination may have influenced the assay results. While they presented no data to back their claims, Gauldie et al. (1992) speculated that contamination from the sediment might result in the radiochemical assay of material which was not incorporated into the otolith structure. Such contamination would presumably affect the whole otoliths more than the otolith cores, yet there was no apparent effect on the accuracy of the whole-otolith assays. Gauldie et al. (1992) also suggested that a gaseous intermediate in the radioactive decay series might diffuse out of the otolith, and thus invalidate the use of radiochemical dating for ageing fish. However, their logic is flawed when applied to the Th-228/Ra-228 decay series, since it has no gaseous intermediate. Therefore, diffusion out of the otolith is not possible.

Given its value for ageing short-lived tropical fish species, we foresee the need for continued develop- ment of Th-228/Ra-228 age determinations. Reduction in the background counts associated with the radium assay is, at present, in most need of refinement. In light of the relative ease of modelling otolith growth in short-lived species, radiochemical assays of whole otoliths should play an increasing role in the age determination of heretofore difficult-to-age adult tropical fishes.

Acknowledgements. We thank J. Hamel for her expert technical assistance, R. Nelson for undertaking the radiochemical analyses, and Dr R. K. Mohn for valuable guidance with the calculus. We also thank the anonymous reviewers for their helpful comments.

\section{LITERATURE CITED}

Bennett, J. T., Boehlert, G. W., Turekian, K. K. (1982). Confirmation of longevity in Sebastes diploproa (Pisces: Scorpaenidae) from $\mathrm{Pb}-210 / \mathrm{Ra}-226$ measurements in otoliths. Mar. Biol. 71: 209-215

Campana, S. E., Neilson, J. D. (1985). Microstructure of fish otoliths. Can. J. Fish. Aquat. Sci. 42: 1014-1032

Campana, S. E., Zwanenburg, K. C. T., Smith, J. N. (1990). $210-\mathrm{Pb} / 226-\mathrm{Ra}$ determination of longevity in redfish. Can. J. Fish. Aquat. Sci. 47: 163-165

Fenton, G. E., Ritz, D. A., Short, S. A. (1990). 210-Pb/226-Ra disequilibria in otoliths of blue grenadier, Macruronus novaezelandiae: problems associated with radiometric ageing. Aust. J. mar. Freshwat. Res. 41: 467-473

Fenton, G. E., Short, S. A., Ritz, D. A. (1991). Age determination of orange roughy, Hoplostethus atlanticus (Pisces: Trachichthyidae) using $\mathrm{Pb}-210: \mathrm{Ra}-226$ disequilibria. Mar Biol. 109: 197-202

Gauldie, R. W., Coote, G. C., Mulligan, K. P., West, I. F. (1992). A chemical probe of the microstructural organization of fish otoliths. Comp. Biochem. Physiol. 102A: 533-545

Gunn, J. S., Harrowfield, I. R., Proctor, C. H., Thresher, R. E. (1992). Electron probe microanalysis of fish otoliths evaluation of techniques for studying age and stock discrimination. J. exp. mar. Biol. Ecol. 158: 1-36

Hall, D. N. F. (1955). Recent developments in the Barbadian flyingfish fishery and contributions to the biology of the flyingfish, Hirundichthys affinis (Gunther 1866). Colon. Off. Fish. Publ. 7: 1-41

Kalish, J. M. (1989). Otolith microchemistry: validation of the effects of physiology, age and environment on otolith composition. J. exp. mar. Biol. Ecol. 132: 151-178

Khokiattiwong, S. (1988). Seasonal abundance and reproduction of the flyingfishes Firundichthys affinis and Parexocoetus brachypterus near Barbados. M.Sc. thesis, University of McGill

Koide, M., Bruland, K. W. (1975). The electrodeposition and determination of radium by isotopic dilution in seawater and in sediments simultaneously with other natural radionuclides. Analytica chim. Acta 75: 1-19

Lao, M. R. (1989). Distribution and abundance of flotsam, larval fish and juvenile fish off Barbados, with particular reference to the Exocoetidae. M.Sc. thesis, University of McGill, Montreal

Le Foll, D., Brichet, E., Reyss, J. L., Lalou, C., Latrouite, D. (1989). Age determination of the spider crab Maja squinado 
and the European lobster Homarus gammarus by 228 Th/228-Ra chronology: possible extension to other crustaceans. Can. J. Fish. Aquat. Sci. 46: 720-724

Lewis, J. B., Brundritt, J. K., Fish, A. G. (1962). The biology of the flyingfish, Hirundichthys affinis. Bull. mar. Sci. Gulf Caribb. 12: 73-94

Mahon, R. (1989). Developing a management strategy for the flyingfish fishery of the eastern Caribbean. Proc. Gulf Caribb. Fish. Inst. 39: 389-403

Mahon, R., Oxenford, H., Hunte, W. (eds.) (1986). Development strategies for flyingfish fisheries of the eastern Caribbean. International Development Research Centre Man. Rep. $128 \mathrm{e}$

Moran, S. B., Buesseler, K. O. (1992). Short residence time of colloids in the upper ocean estimated from U-238-Th-234 disequilibria. Nature $359 ; 221-223$

Oxenford, H. (1986). Synopsis of the biological data on the four-winged flyingfish Hirundichthys affinis. In: Mahon, R., Oxenford, H., Hunte, W. (eds.) Development strategies for flyingfish fisheries of the eastern Caribbean. International Development Research Centre Man. Rep. 128 e, p. $51-88$

Oxenford, H. A. (1993). Movements of flyingfish (Hirundichthys affinis) in the eastern Caribbean. Bull mar. Sci. (in press)

Ricker, W. E. (1979). Growth rates and models. In: Hoar, W. S., Randall, D. J., Brett, J. R. (eds.) Fish physiology, Vol. 8. Academic Press, New York, p. 677-743

This article was submitted to the editor
Smith, J. N., Nelson, R., Campana, S. E. (1991). The use of $\mathrm{Pb}-210 / \mathrm{Ra}-226$ and Th-228/Ra-228 disequilibria in the ageing of otoliths of marine fish. In: Kershaw, P. J., Woodhead, D. S. (eds.) Radionuclides in the study of marine processes. Elsevier Applied Science, New York, p. $350-359$

Storey, K. W. (1983). Aspects of the biology and fishery of the flyingfish, Hirundichthys affinis, at Barbados. M.Sc. thesis, Univ. West lndies, Cave Hill

Summerfelt, R. C., Hall, G. E. (eds.) (1987). Age and growth of fish. Iowa State University Press, Ames

Tsukamoto, K. (1988). Otolith tagging of ayu embryo with fluorescent substances. Nippon Suisan Gakk. 54: $1289-1295$

Turekian, K. K., Cochran, J. K., Kharkar, D. P., Cerrato, R. M., Vaisnys, J. R., Sanders, H. L., Grassle, J. F., Allen, J A. (1975). Slow growth rate of a deep-sea clam determined by Ra-228 chronology. Proc. natl Acad. Sci. U.S. 72 : 2829-2832

Turekian, K. K., Cochran, J. K., Nozaki, Y. (1982). Determination of shell deposition rates of Arctica islandica from the New York Bight using natural Ra-228 and Th-228 and bomb-produced C-14. Limnol. Oceanogr. 27: 737-741

Weldon, B. A., Cailliet, G. M., Flegal, A. R. (1987). Comparison of radiometric with vertebral band age estimates in four California elasmobranchs. In: Summerfelt, R. C., Hall, G. E. (eds.) Age and growth of fish. Iowa State University Press, Ames, p. 301-315

Manuscript first received: April 30, 1993

Revised version accepted. July 13, 1993 